- ORIGINAL ARTICLE

Volume 10 Issue 12018

DOI: 10.21315/eimj2018.10.1.4

ARTICLE INFO

Submitted: 26-07-2017

Accepted: 06-02-2018

Online: $30-03-2018$

\section{Students' Perceptions about the Immediate Feedback Assessment Technique (IF-AT) in Team- Based Learning}

\author{
Shahid Hassan², Imtiaz Begum², Nabiha Gul Hassan³ \\ ${ }^{1} I M U$ Centre for Education, International Medical University, Kuala \\ Lumpur, MALAYSIA \\ ${ }^{2}$ Department of Medicine, Ziauddin University Karachi, PAKISTAN \\ ${ }^{3}$ Department of Community Health, Faculty of Medicine and Health \\ Sciences, Universiti Putra Malaysia, Selangor, MALAYSIA
}

To cite this article: Hassan S, Begum I, Gul Hassan N. Students' perceptions about the immediate feedback assessment technique (IF-AT) in team-based learning. Education in Medicine Journal. 2018;10(1):25-34. https://doi.org/10.21315/eimj2018.10.1.4

To link to this article: https://doi.org/10.21315/eimj2018.10.1.4

ABSTRACT

Immediate feedback assessment technique (IF-AT) are self-scoring answer sheets, based on the concepts of immediate feedback for choosing the correct answer in multiple choice questions (MCQs) during group readiness assurance tests (GRATs) in team-based learning (TBL). IF-AT scratch card system rewards a student with partial credit for proximate knowledge. This technique motivates students to pursue learning with just-in-time feedback and gives them the opportunity for collaborative learning and analytic reasoning among group members. A rubric for partial credit is decided pre-hand depending upon the number of options used in MCQs. In this study, we assessed students' perception about immediate feedback assessment technique before and after the training. To determine students' perception of the IF-AT scratch card system in instruction and assessment. Students perceptions about the IF-AT system has been explored using a 25-item questionnaire administered to 60 students assigned randomly to control and training groups using pre-test and post-test analysis. Paired-sample $t$-test and independent-sample $t$-test statistics were employed and the data was analysed. Descriptive statistics observed for mean (SD) was found greater in trained group $=58.48(4.87)$ vs. control group $=66.43$ (5.81) with $t$-statistics significant at $p=<0.001$. A significant difference in mean (SD) of pre-test minus post-test scores (5.16) of control and trained group $=5.37$ (4.85) and $10.53(8.36)$ respectively was also found with independent $t$-test analysis. It was found highly significant with $t=-2.92, p<0.05$ and the effect size of $78.1 \%$, established by Cohen's $d$ criteria. The IF-AT system provides an individualised and instantaneous instruction as feedback in an assessment, which is marked with collaborative learning as in team-based learning. The IF-AT system promotes analytic reasoning with problem solving skills through partial credit for proximate knowledge. Students' perceive the concept of immediate feedback and partial credit for proximate knowledge as the most important features of the IF-AT scratch card system.

Keywords: IF-AT scratch-card system, MCQ, Immediate feedback, Partial credit, Collaborative learning

Professor Dr. Shahid Hassan, IMU Centre for Education, International Medical University, 126 Jalan Perkasa, Bukit Jalil, 57000 Kuala Lumpur, Malaysia | Email: shahidhassan@imu.edu.my 


\section{INTRODUCTION}

The immediate feedback assessment technique (IF-AT) "scratch-and-win" answer sheets was first introduced and refined by Mike Epstein at Rider University (1). IF-AT answer sheet has a row of boxes for each question that can be scratched one by one until the correct answer, indicated by a star $\left(^{\star}\right)$, is found. The importance of IF-AT cards is that it initiates discussion among the students in order to generate a consensus and shared understanding to choose which box to scratch next in order to find the correct answer (2). While using IFAT cards in Team Readiness Assurance Test (TRATs) of team-based learning (TBL) it has been observed that even students who are quieter also tend to participate and share opinions and reasoning with group members (3). This process helps to avoid the domination of discussion by enthusiastic and overactive members in the group, a common problem in group-based learning. The other powerful feature of these cards is the immediate, corrective feedback $(4,5)$. Assuming students are provided an opportunity to learn when wrong in their choices of answers by the immediate feedback, while quite students with correct and valid answers are encouraged and invited to participate more actively in team discussion by the teammates (6).

IF-AT uses self-scoring answer sheets based on the concept of providing immediate feedback for choosing the correct answer in MCQs with One Best Answer (OBA) format in formative assessment or TRATs in TBL (7). However, these answer sheets are not used in the Individual Readiness Assessment Tests (IRATs) because establishing the correct answer will enable the team members of each group to correctly answer the items in TRATs phase of TBL. The procedure involved in IF-AT is that students scratch off the covering of one of four or five boxes in order to find a star $\left(^{\star}\right)$, which indicates the correct answer. If they find the star on the first try, they receive full credit. If not, they continue to scratch until they do find the mark, however their score is reduced with each unsuccessful attempt they make. This allows teams to receive partial credit for their relatively correct answer suggestive of their approximate knowledge.

IF-AT scratch card system considers rewarding a student with partial credit exactly like a student with relatively less authentic knowledge in an essay examination is acknowledged by receiving some marks although comparatively less than those for authentic answers (8). This keeps the student engaged and motivated to learn in a collaborative manner in TBL. Literature has shown the effectiveness of using the IF-AT to teach students while testing their knowledge (9). IF-AT can also be conveniently be used by incorporating it into formative or continuous/end of the posting assessment in an undergraduate programme. Partial credit for "proximate" knowledge motivates the student to consistently pursue the correct answer (10). Instructors are free to decide on partial marking scores, however research has established that awarding any amount of partial credit until discovering the correct answer is a motivator that promotes collaborative learning if TBL method is used (9).

A decremented scoring system is used following discussions among group members before deciding to scratch the next box after an incorrect answer. The scoring rubric of an item will depend on the numbers of options used in MCQs. One possible rubric for an IF-AT score for an item with four options could be; three points for the correct answer on the first scratch, two points for the correct answer on the second scratch, one point for the correct answer on the third scratch, and zero points if they scratch off all four boxes to reveal the correct answer. This process keeps the group members engaged with an item to continue the discussion with until they reach the correct answer. The decremented process in the IF-AT system keeps students motivated to consistently pursue learning with the incentive of partial credit for "proximate" knowledge (1). The process in which a 
student can gradually narrow down a correct choice through reasoning likely understands more than a student who attempts to answer based on guesses (10) (see Table 1).

In the author's opinion, using the IF-AT in TRATs is the single most powerful tool for promoting teamwork in TBL. Using IFAT scratch cards will have a direct impact on the effectiveness of implementing TBL. The IF-AT scratch cards is simple to use by students once an instructor has prepared the MCQ (OBA) items co-ordinated with the IF-AT cards. The correct answer ranking of an option in each item is followed with same order of correct answers provided in the IF-AT card serial depending on the series used. Students in IF-AT system receive the point value rank for the correct answer. One box is scratched at a time to find the correct answer indicated by a star and if a box appears empty then the student move to next choice and repeats this until the correct answer is found. Students' subsequently receive partial credit for the number of boxes they have scratched (see Figure 1). Any dishonesty displayed by students in an attempt to leak the correct answer in the box identified with a star will hardly be possible because stars used for correct answers vary in each row (11).

Research has proved that the difference in TRAT and IRAT scores represents increased team performance over individual performance (10). However, same MCQ items that have been used in the IRATs cannot be used in the TRATs because once correct answer is established it will enable the team of same member to correctly answer the items in TRATs assessment. Research to compare IRATs with TRATs can be carried out and statistically evaluated using equivalent form method of MCQ developed for IRATs and TRATs items (12) respectively. The research has established the importance of partial credit until the correct answer has been found, which ultimately provides immediate feedback that enhance students' performance and motivation (6). Delayed feedback whether short or long fails to provide that benefit. Research has shown that any feedback that offers no change in students' scores once granted, do not motivate to learn as much as partial credit will encourage them for "proximate" knowledge and motivation in pursuing the correct answer (1). A sample of point values that different instructors are currently using for the first and the subsequent correct responses is shown in the Table 1.

To match IF-AT sheet with their tests, IFAT cards are set for their correct answers indicated with a small star in a particular order and it is the instructor who arranges the answer to match the selected card. Answer patterns are flexible to change and are preselected within a series to prevent the students from memorising or predicting the answers (13). Each card has an identifying key number at the bottom that can be removed by the teacher. The IF-AT cards are available in lengths of 10,25 , and 50 questions and with either four options (AD) or five options (A-E) and can be ordered to purchase depending on the institution's policy (11) (see Figure 1). In TRATs phase of assessment in TBL, the instructor may take the role of an expert planner or manager and students can still do without his direct involvement in the learning process as the IF-AT model evidently provides immediate feedback (2). The instructor can set up a learning environment that is likely to enhance their performance by empowering them to take full control of and responsibility for their own learning by providing an immediate feedback system. 
Table 1: Suggested IF-AT scratch card system rubric with different options and number of attempts

\begin{tabular}{|c|c|c|c|}
\hline & 5-Answer Options Test & 4-Answer Options Test & 3-Answer Options Test \\
\hline \multirow[t]{2}{*}{1} & Example A & Example A & Example A \\
\hline & $\begin{array}{l}10 \text { Points - first choice } \\
5 \text { Points - second try } \\
2 \text { Points - third try } \\
1 \text { Point - fourth try } \\
0 \text { No credit - fifth try }\end{array}$ & $\begin{array}{l}5 \text { Points - first choice } \\
2 \text { Points - second try } \\
1 \text { Points - third try } \\
0 \text { No credit - fourth try }\end{array}$ & $\begin{array}{c}3 \text { Points - first choice } \\
1 \text { Point - second try } \\
0 \text { Point - third try }\end{array}$ \\
\hline \multirow[t]{2}{*}{2} & Example B & Example B & Example B \\
\hline & $\begin{array}{l}5 \text { Points - first choice } \\
3 \text { Points - second try } \\
2 \text { Points - third try } \\
1 \text { Point - fourth try } \\
0.5 \text { Point - fifth try }\end{array}$ & $\begin{array}{l}5 \text { Points - first choice } \\
3 \text { Points - second try } \\
2 \text { Points - third try } \\
1 \text { Point - fourth try }\end{array}$ & $\begin{array}{l}5 \text { Points - first choice } \\
3 \text { Points - second try } \\
1 \text { Point - third try }\end{array}$ \\
\hline \multirow[t]{2}{*}{3} & Example C & Example C & Example C \\
\hline & $\begin{array}{c}5 \text { Points - first choice } \\
3 \text { Points - second try } \\
2 \text { Points - third try } \\
1 \text { Point - fourth try } \\
0 \text { Point - fifth try }\end{array}$ & $\begin{array}{l}5 \text { Points - first choice } \\
3 \text { Points - second try } \\
1 \text { Point - third try } \\
0 \text { No credit - fourth try }\end{array}$ & $\begin{array}{l}5 \text { Points - first choice } \\
2 \text { Points - second try } \\
0 \text { Point - third try }\end{array}$ \\
\hline
\end{tabular}

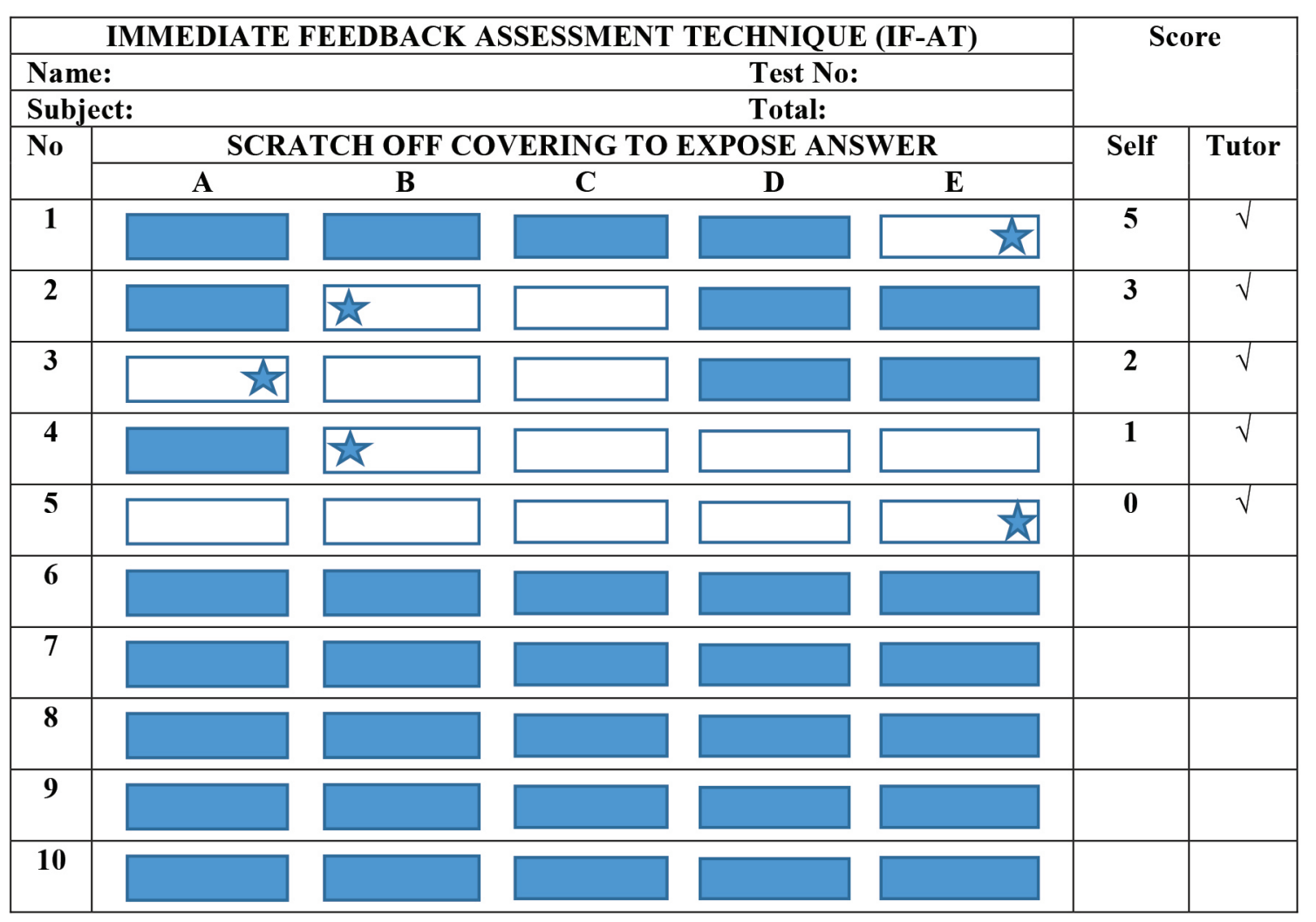

Figure 1: Decremented IF-AT scoring with five option list of 1 correct answer and 4 distractors and scoring system of 5 Points - First Choice, 3 Points - Second Try, 2 Points - Third Try, 1 Point - Fourth Try, and 0 Point Fifth Try. 


\section{MATERIAL AND METHOD}

A total of 60 participants from the 2015, Year IV class of the MBBS programme, in the Faculty of Medicine at Universiti Sultan Zainal Abidin (UniSZA) were randomly assigned to a control and training group. The control group received no interventional training, whereas the training group underwent a special training programme to learn about the various aspects of the IF-AT scratch card system. All participants of the training group attended a lecture followed by a video demonstration of the IF-AT card utility in OBA format of MCQs.

A 25-item questionnaire (see Appendix) specially developed to evaluate the students understanding of the IF-AT system was administered to both groups. The questionnaire was designed to assess students' awareness about the IF-AT system, its utility in MCQs, and rationale and importance in providing immediate feedback as a special feature. Each item of the IF-AT scratch card questionnaire were provided with three options to choose from: agree, disagree and not sure with a Likert scale of 1-3 (3: indicated agreement, 2: not sure, and 1: dis-agreement). The questionnaire was administered as a "pre-test" to all the 60 randomly assigned participants of both the control and training groups and then the same questionnaires were re-administered as the "post-test" to both groups at different times.

The data comprised of three variables: control and training group (independent variable), pre-test and post-test score (dependant variable) and a variant (difference) of pre-test and post-test score (dependent variable). The research question was whether the interventional training on the IF-AT scratch card system enhanced students' understanding about the immediate feedback and role of IF-AT system in assessment. We anticipated that the training would enhance their knowledge and understanding about IF-AT system with null hypothesis stating a significant difference between the control and training group, indicating that the training group had a better learning experience than the control group.

Inclusion criteria were the students prior engagement and teaching through TBL. Six students were excluded out of a total 66 students. Control group was quarantine when the training group was receiving interventional class on IF-AT scratch cards and its utility. The data was analysed using SPSS Version 21 and the statistical tests used were paired sample $t$-test and independent sample $t$-test. Descriptive and inferential statistics were analysed and interpreted.

\section{RESULT}

In order to test the null hypothesis that the pre-test and post-test scores are equal, a dependent sample $t$-test was performed. However, to meet the assumption of normality distributed difference scores were examined and it was found satisfactory as the skewness and kurtosis levels were estimated at 0.254 and 1.313 , respectively, which is less than the maximum allowance guidelines for $t$-test that of skewness $<0.8$ and kurtosis $<2.0$. It was also noted that the correlation between the two scores were also highly correlated at $r=0.737$, suggesting that dependent sample $t$-test is appropriate for this study. A difference of mean score $=7.950$ was found between the mean of post-test $=66.43(5.812)$ and mean of pretest $=58.48$ (4.876). The null hypothesis of equal mean score was rejected, $t$ (59) $=8.478, p<0.001$ (see Table 2).

The independent-sample $t$-test to analyse the difference between the two groups measured independently of each other was also performed. Descriptive statistics showed that there is an increase in mean perception for better knowledge in trained group $=10.53(8.36)$ compared to control group $=5.37$ (4.85) with a mean difference of -5.167 (see Table 3). Test of homogeneity of variance before analysing the $t$-test statistics 
was met with Levene's test insignificant at $p=0.289$. A significant difference in mean (SD) of pre-test minus post-test at -5.16 with pre-test mean $=-5.37(4.85)$ post-test $=10.53(8.36)$ was found respectively. The $t(58)=-2.296$ was also significant with $p<0.05$ (see Table 3) between the two groups characterised with and without training in IF-AT system respectively (see Table 3). Looking for the effect size, Cohen's $d$ analysis of two groups as the measure of magnitude of mean difference, which tells about the variation of one variable responsible for variation of other variable in group can be performed. However, SPSS does not calculate this in independent $t$-test option but this can be calculated manually once the null hypothesis is rejected, using the formula of difference of means (5.16) divided by average of SD (6.60). On calculating with this formula effect size was found relatively larger $(0.781)$ by standard of Cohen's $d$. The criteria for Cohen's $d$ suggest, $d=0.2$ small effect, $d=0.5$ medium effect, and $d=0.8$ large effect.

Table 2: Score before and after the interventional training by paired-sample $t$-test

\begin{tabular}{lccccc}
\hline Variable & $\begin{array}{c}\text { Pre-test mean } \\
\text { (SD) }\end{array}$ & $\begin{array}{c}\text { Post-test mean } \\
(\text { SD })\end{array}$ & $\begin{array}{c}\text { Mean score difference } \\
(95 \% \mathrm{CI})\end{array}$ & $\boldsymbol{t}$-statistics & $\boldsymbol{p}$-value \\
Score & $66.43(5.81)$ & $58.48(4.87)$ & $\begin{array}{c}7.95 \\
(6.07,9.82)\end{array}$ & 8.47 & 0.000 \\
& & & & \\
\hline
\end{tabular}

Table 3: Mean score before and after the training by independent-sample $t$-test

\begin{tabular}{lccccc}
\hline \multicolumn{1}{c}{ Variable } & $\begin{array}{c}\text { Control mean } \\
\text { (SD) }\end{array}$ & $\begin{array}{c}\text { Training } \\
\text { mean (SD) }\end{array}$ & $\begin{array}{c}\text { Mean score } \\
\text { difference (95\% CI) }\end{array}$ & t-statistics & $\boldsymbol{p}$-value \\
$\begin{array}{l}\text { Difference } \\
\text { Post-test -Pre- } \\
\text { test }\end{array}$ & $5.37(4.85)$ & $10.53(8.36)$ & $\begin{array}{c}5.16 \\
(1.63,8.70)\end{array}$ & -2.92 & 0.005 \\
\hline
\end{tabular}

\section{DISCUSSION}

The IF-AT was developed and refined by a psychology professor who specialised in human learning and memory. The concepts involved in the IF-AT creation were based on three principles: (a) Immediate feedback is more beneficial for learning than delayed feedback (14); (b) The best assessment instrument is not the one, which simply assesses but it also teaches; (c) The last response attempted by students on a test item is not frustrating rather a sense of achieving the correct answer for retention. However, the overall use of multiple choice items and IF-AT scoring techniques reported in literature is only $28 \%$ (10). Hardly any institution in Malaysia has introduced this method and simultaneously teaching techniques by providing immediate feedback. The present study aimed at creating awareness about the immediate feedback assessment technique and the associated benefits of using this method in assessments. The present study has shown a significant difference in understanding and persuasiveness (15) of concept about the IF-AT system between those whose received training vs. those who did not receive any training, and this was measured through a pre-test and post-test analysis of questionnaire based survey.

The descriptive and the inferential statistics showed significant difference between posttest and pre-test $(p<0.001)$ in general across the 60 participants, indicating that training with IF-AT system worked better for training group compared to control group. The findings of independent $t$-test with highly significant difference between the two groups $(p>0.05)$ and effect size of 
$78.10 \%$, which relatively larger by Cohen's $d$ criteria to explain the effects of two variables and this confirms that the training has worked to enhance the existing knowledge and understanding about the IF-AT scratch card system and will be useful when IFAT system is employed initially in group assurance readiness test of team-based learning already practiced in Year Four of MBBS programme at UniSZA. The findings of independent-sample $t$-test showed a significant difference of mean in post-test minus pre-test. This was found consistent with paired-sample $t$-test.

The literature recommendation of same MCQ items to be avoided in IRATs and TRATs simply because once correct answer is established it will enable the team of same member to correctly answer the items in TRATs assessment has not been practiced by this author, who has a different experience of using the same OBA items for IRAT and TRAT however, restricting the feedback until both IRAT and TRAT is accomplished. It has been observed that students perform better in TRATs than IRATs. This feedback has encouraged the students to have collaborative learning for its impact of transferring the information for long-term retention.

In the changing trend of adapting to interactive teaching strategy employing TBL in Faculty of Medicine in UniSZA, the current study will have positive impact on progressive change in curriculum practice. The entire process of introducing IF-AT scratch card system was enthusiastically welcomed by the training group responding to Item 24 and 25 of IF-AT questionnaire. Immediate feedback (Items 13, 14, 15, 16 and 19) and the concept of partial credit in OBA (Item 20) were also highly applauded by the participants after having introduced to the IF-AT scratch card system. Survey has also obtained students consent to employ IF-AT scratch card system routinely in OBA format of MCQs (Item 10). This will eventually promote learning with better analytic reasoning skills developed through persistent use of IF-AT scratch cards in assessment.

\section{CONCLUSION}

The IF-AT provides a valuable learning experience when students are given the opportunity to engage in problem solving situations and receive an immediate feedback upon suggesting solutions. The process of finding the right answer in the IF-AT model continues until a student scratches off the correct box. IFAT provides an individualised, instantaneous instruction as if an instructor is around the student and providing him the feedback in an "instructional session" with affirmation of correct or incorrect answer that is always encouraged in a collaborative learning. The concepts of immediate feedback and partial credit for proximate knowledge have been acknowledged as the most important features of IF-AT scratch card system by the students. The IF-AT system is also appreciated for promote analytic reasoning learning skills among students who look forward to practice IF-AT scratch card system in MCQ assessment and team readiness assurance test in TBL sessions in the Faculty of Medicine at UniSZA.

\section{ACKNOWLEDGEMENTS}

We would like thank the students of Year Four of the MBBS programme at UniSZA for participating in this survey and completing the questionnaire. 


\section{APPENDIX}

\begin{tabular}{|c|c|c|c|c|}
\hline No. & Items & & Response & \\
\hline 1 & $\begin{array}{l}\text { In my institution students do not routinely receive feedback } \\
\text { on their answers to examination questions. }\end{array}$ & Agree & Disagree & Not Sure \\
\hline 2 & $\begin{array}{l}\text { Students are interested to receive feedback on their MCQ } \\
\text { answers at least in formative (continuous/end of posting) } \\
\text { assessment if not in summative assessment. }\end{array}$ & Agree & Disagree & Not Sure \\
\hline 3 & $\begin{array}{l}\text { Practice of feedback to MCQ items in assessment enhances } \\
\text { learning among students. }\end{array}$ & Agree & Disagree & Not Sure \\
\hline 4 & $\begin{array}{l}\text { If opportunity given students will like to receive immediate } \\
\text { feedback on their response to MCQ items. }\end{array}$ & Agree & Disagree & Not Sure \\
\hline 5 & $\begin{array}{l}\text { Immediate feedback (within } 12 \text { hours) is considered to } \\
\text { enhance learning more effectively than delayed feedback } \\
\text { (after } 12 \text { hours). }\end{array}$ & Agree & Disagree & Not Sure \\
\hline 6 & $\begin{array}{l}\text { Immediate feedback on MCQ items to individual candidate is } \\
\text { possible in formative assessment. }\end{array}$ & Agree & Disagree & Not Sure \\
\hline 7 & $\begin{array}{l}\text { I know of an immediate feedback system called, IF-AT } \\
\text { available as scratch cards. }\end{array}$ & Agree & Disagree & Not Sure \\
\hline 8 & $\begin{array}{l}\text { IF-AT scratch card system rewards students with partial credit } \\
\text { in MCQ (OBA) performance. }\end{array}$ & Agree & Disagree & Not Sure \\
\hline 9 & $\begin{array}{l}\text { IF-AT card are used to answer MCQ items, scratching one box } \\
\text { at a time in an attempt to find correct answer. }\end{array}$ & Agree & Disagree & Not Sure \\
\hline 10 & $\begin{array}{l}\text { IF-AT scratch card system used in assessment is suitable for } \\
\text { OBA format of MCQ assessment. }\end{array}$ & Agree & Disagree & Not Sure \\
\hline 11 & $\begin{array}{l}\text { IF-AT scratch card is not a passive act of lucky draw but an } \\
\text { actively performed sequence of activity that ensures students' } \\
\text { engagement and test of higher order thinking. }\end{array}$ & Agree & Disagree & Not Sure \\
\hline 12 & $\begin{array}{l}\text { Introducing the IF-AT system will benefit students in test of } \\
\text { OBA items since students review the stem and the options list } \\
\text { several times before scratching each box. }\end{array}$ & Agree & Disagree & Not Sure \\
\hline 13 & $\begin{array}{l}\text { Students are interested to have feedback about their } \\
\text { wrongly or correctly responded MCQ items in the midst of an } \\
\text { assessment. }\end{array}$ & Agree & Disagree & Not Sure \\
\hline 14 & $\begin{array}{l}\text { Using IF-AT scratch and immediate feedback can help } \\
\text { enhance students' learning while being assessed. }\end{array}$ & Agree & Disagree & Not Sure \\
\hline 15 & $\begin{array}{l}\text { Receiving immediate feedback on wrong answers of } \\
\text { MCQ items during assessment will not make students } \\
\text { uncomfortable. }\end{array}$ & Agree & Disagree & Not Sure \\
\hline 16 & $\begin{array}{l}\text { Immediate feedback on MCQ answers during the assessment } \\
\text { rather motivates students' learning. }\end{array}$ & Agree & Disagree & Not Sure \\
\hline 17 & $\begin{array}{l}\text { IF-AT scratch cards can effectively be used in TBL method of } \\
\text { teaching. }\end{array}$ & Agree & Disagree & Not Sure \\
\hline 18 & $\begin{array}{l}\text { Is it the Team Readiness Assessment Test (TRAT) phase of TBL } \\
\text { that IF-AT scratch cards can be used. }\end{array}$ & Agree & Disagree & Not Sure \\
\hline 19 & $\begin{array}{l}\text { IF-AT scratch cards can be used to promote collaborative team } \\
\text { learning with just-in-time feedback. }\end{array}$ & Agree & Disagree & Not Sure \\
\hline
\end{tabular}


ORIGINAL ARTICLE | Students' Perception about IF-AT

\begin{tabular}{|c|c|c|c|c|}
\hline No. & Items & & Response & \\
\hline 20 & $\begin{array}{l}\text { Rewarding relatively incorrect answers by "partial credit" is an } \\
\text { exciting idea in answering the OBA items using IF-AT system. }\end{array}$ & Agree & Disagree & Not Sure \\
\hline 21 & $\begin{array}{l}\text { Using IF-AT scratch cards students practice their analytic } \\
\text { reasoning skills more thoroughly then attempting MCQ items } \\
\text { without using the scratch cards. }\end{array}$ & Agree & Disagree & Not Sure \\
\hline 22 & $\begin{array}{l}\text { Cheating on examination in MCQ is possible with IF-AT scratch } \\
\text { cards if one scratches minimally to expose the star }(\xi) \text {, a sign } \\
\text { indicating correct answer. }\end{array}$ & Agree & Disagree & Not Sure \\
\hline 23 & $\begin{array}{l}\text { There is no ONE specific pattern of partial credit while } \\
\text { using the IF-AT scratch cards and it depends on supervisor's } \\
\text { decision to select the marking scheme. }\end{array}$ & Agree & Disagree & Not Sure \\
\hline 24 & $\begin{array}{l}\text { IF-AT system will be effective in controlling the domination of } \\
\text { more vocal students in TBL assessment. }\end{array}$ & Agree & Disagree & Not Sure \\
\hline 25 & $\begin{array}{l}\text { I would like the administration in my institution to introduce } \\
\text { IF-AT scratch cards in OBA assessment. }\end{array}$ & Agree & Disagree & Not Sure \\
\hline
\end{tabular}




\section{REFERENCES}

1. Epstein ML, Epstein BB, Brosvic GM. Immediate feedback during academic testing. Psychological Reports. 2001;88:889-94. https://doi.org/10.2466/ pro.2001.88.3.889

2. Cotner S, Baepler P, Kellerman A. Scratch this! The IF-AT as a technique for stimulating group discussion and exposing misconceptions. Journal of College Science Teaching. 2008;37(4):48-53.

3. Su AY. The impact of individual ability, favourable team member scores and student perception of course importance on student preference of team-based learning and grading methods. Adolescence. 2004. 42;805-26.

4. Carmichael J. Team-based learning enhances performance in introductory biology. Journal of College Science Teaching. 2009. 38(4):54-61.

5. Haberyan A. Team-based learning in an industrial/organizational psychology course. North American Journal of Psychology. 2007;9:143-52.

6. Team-Based Learning, University of Central Missouri. IF-AT answer sheet. 5/18/2015 http://faculty.ucmo.edu/teambasedlearning/ ifat.htm; p. 1-2.

7. Epstein BB, Brosvic GM. 2002. Immediate feedback assessment technique promotes learning and corrects inaccurate first responses. The Psychological Record. 52:187201. http://doi.org/10.1007/BF03395423.
8. Michaelsen LK, Parmelee DX, McMahon KK, Levine RE. Team-based learning for health professions education: a guide to using small groups for improving learning. Sterling, VA: Stylus; 2008.

9. Gardner A, Willey K. Critical conversations: how collaborative learning activities can prepare students for structural engineering practice. Proceedings of the 2010 AaeE Conference, University of Technology, Sydney, Australia. 5-8 December 2010.

10. Michaelsen LK, Knight AB, Fink LD. Teambased learning: a transformative use of small groups. Westport, CT: Praeger; 2002.

11. Clark MC, Nguyen HT, Bray C, Levine RE. 2008. Team-based learning in an undergraduate nursing course. Journal of Nursing Education. 47:111-7. https://oi. org/10.3928/01484834-20080301-02

12. Hefley T, Tyre AJ. Favourable team scores under the team-based learning paradigm: a statistical artefact. RURALS: Review of Undergraduate Research in Agricultural and Life Sciences. 2011;6(1):1.

13. Whitehead J. The immediate feedback assessment technique. Teaching Perspectives - St Thomas University's Teaching Newsletter. 2012;17(Fall):1.

14. Epstein Educational Enterprise. Use of IFAT. p. 1-2. [cited 2015 May 18]. http://www. epsteineducation.com/home/about/uses.aspx.

15. Slepkov AD. Integrated testlets and the immediate feedback assessment technique. Physics Education. 2013 August 20. https:// arxiv.org/abs/1308.4365 